\title{
Development of Moisture and Ash Based Correlation for the Estimation of Mineral Matter in High Ash Indian Coal
}

\author{
M. K. Saini ${ }^{*}$, P. K. Srivastava ${ }^{2}$, N. Choudhury ${ }^{3}$ \\ ${ }^{1}$ Resource Quality Assessment, CSIR-Central Institute of Mining \& Fuel Research, Regional Center, Ranchi, \\ India \\ ${ }^{2}$ Applied Chemistry, Birla Institute of Technology, Regional Center, Deoghar, India \\ ${ }^{3}$ Resource Quality Assessment, CSIR-Central Institute of Mining \& Fuel Research, Digwadih Campus, Dhanbad, \\ India \\ Email: saini.manojkumar@gmail.com
}

Received 10 February 2015; accepted 12 May 2015; published 15 May 2015

Copyright (C) 2015 by authors and Scientific Research Publishing Inc.

This work is licensed under the Creative Commons Attribution International License (CC BY). http://creativecommons.org/licenses/by/4.0/

(c) ()

\begin{abstract}
The experimental determination of mineral matter in coal is a tedious as well as time consuming process, and requires highly skilled analyst to carry out the chemical analysis of coal and ash. On the other hand, determination of moisture and ash is relatively easy using moisture oven and muffle furnace and can be determined anywhere with little care. Most of the methods reported till date for the evaluation of mineral matter in coal involves indirect determination of mineral matter using high temperature ash as one parameter. All these methods offer conversion of ash yield into mineral matter with the help of correlations based on certain assumptions. Although, the method for direct determination of mineral matter by chemical analysis is also reported, but is of little use as it requires extensive chemical analysis. In this study mineral matter is determined directly by oxygen plasma asher in coal samples collected from different regions of India. The results obtained were compared with those obtained by existing correlations. It has been observed that all the existing correlations including Parr's, are found to be unrealistic for high ash Indian coal. An attempt has been made to develop a new correlation for the estimation of mineral matter based on two simple parameter i.e. moisture content and ash yield. Present model was developed after analyzing 75 coal samples. The developed correlation appears to be more simple and better and is represented as Mineral $\operatorname{Matter}(\mathrm{MM})=0.74($ Moisture $)+1.17($ Ash $)$.
\end{abstract}

\section{Keywords}

Ash Yield, Low Temperature Ashing, Mineral Matter, Moisture Content

\footnotetext{
${ }^{*}$ Corresponding author.
}

How to cite this paper: Saini, M.K., Srivastava, P.K. and Choudhury, N. (2015) Development of Moisture and Ash Based Correlation for the Estimation of Mineral Matter in High Ash Indian Coal. International Journal of Clean Coal and Energy, 4, 33-42. http://dx.doi.org/10.4236/ijcce.2015.42004 


\section{Introduction}

Coal is a solid fossil fuel and it incorporates inorganic materials from the original swamp environment or any that may have been washed or blown into the accumulating coal seam. The mineral described as "mineral matter" (MM) in coal encompasses dissolved salts in the pore water and inorganic elements associated with the organic compounds, as well as discrete crystalline and non-crystalline mineral particles [1]. Coal can be regarded for many purposes as consisting of two classes of material; organic components or macerals and a range of minerals and other inorganic constituents, broadly referred to as mineral matter. The mineral matter in coal, like the organic matter, is a product of the processes associated with peat accumulation and rank advance, as well as changes in surface fluids and other aspects of sediment diagenesis. Indian coal is believed to be of drift origin, where coals were formed from plant materials of terrestrial vegetation which were transported in to lakes, river, valleys and estuaries or even in to the sea. The drift theory is favoured by the similarity between coal and the sedimentary rock. During the period of deposition of the plant debris there could be periods during which heavy quantities of mud were carried down to form intervening layers. This is evident in the coal seams in almost all region of India. Indian coals suffer from the great disadvantage that the mineral matter content is not only high but also of an intimately associated [2] [3] type due to its drift origin. Furthermore, during the mining operation inadvertently (or inevitably) some rock material gets mixed with the coal. The inorganic fraction is a diluent, displacing more useful organic matter with a non-combustible component that leaves an ash residue when the coal is burned, or that needs to be removed as slag from the blast furnace during metallurgical processing. Although the mineral matter in coal is an undesired impurity, knowledge of its amount and composition is an important marker for the genetic history of coal [4]. The mineral matter in the coal also provides information on the depositional conditions and geological history of coal bearing sequences and individual coal beds.

Coal produced by operating mines typically contains additional mineral constituents derived from bands and other concentrations of non-coal material within the seam. They may also possibly contain some fragments of non-coal rock derived from contamination of the mined product by roof or floor strata. This portion of the mineral matter is called extraneous mineral matter and may be at least partly removed by cleaning processes in coal preparation plants. There is, nevertheless, usually a significant level of mineral matter intimately associated with the macerals, sometimes referred to as inherent mineral matter that cannot effectively be removed by coal preparation techniques. Inherent mineral matter is an unavoidable part of even the cleanest coal product, and must be taken into account along with the macerals in assessing the coal's behavior during handling, storage and use [5] [6]. The bulk of the mineral matter of coal is due to clay or shale consisting of aluminosilicates of different composition. Other major constituents may be calcite, and pyrite, or related matter. When coal burns, shale and other hydrated minerals lose water of hydration while sulphides, sulphates and carbonates usually decompose, or oxides leaves their basic radicals free to combine with excess of silica, if any. The net result is a loss of weight so that the ash of coal is always less than the mineral matter content.

Quantitative analysis of minerals and other inorganics contributes significantly to defining coal quality. For the purpose of the scientific classification of coal, it is necessary to know the proportions of inorganic constituents present, since it is only possible to determine accurately the elementary composition of the organic portion of coal when the proportion of inorganic matter is known. Data from mineral matter determination are used to express other analytical results for the coal to a mineral matter free basis, as needed for classification purposes. Since the inorganic matter may differ from the ash by several percent and the use of the figure would involve large errors in the true carbon content or heat value of pure coal.

Brown et al. in 1959 [7] proposed the determination of mineral matter in coal by Low Temperature Ashing at $370^{\circ} \mathrm{C}$ with some corrections for pyrite, siderite and some clay minerals which undergo irreversible change of mass or crystal structure. Besides the time consuming, its reliability remain under scanner as the mass percentage remaining after such heating is still not necessarily a reliable measure of the total mineral content. Another way of low temperature ashing was also reported by Gluskoter [8] and Frazer [9]. This represents the most reliable method for determination of mineral matter in coal. Precise determination of the mineral matter percentage in coal by low temperature ashing also involves correcting the oxygen-plasma ash yield for any un-oxidised organic carbon residues, and for any sulphur fixed in the low temperature ash from the organic sulphur component [10]. These are often relatively small corrections, however, and for many purposes the proportion of low temperature ash gives an adequate indication of the percentage of mineral matter present [1].

In this study the mineral matter in coals were determined by low temperature ashing by oxygen plasma asher under controlled conditions and utmost care. The mineral matter determined here was compared with those ob- 
tained by other existing correlations. All existing correlations are found to be unrealistic for the coal having ash more than 35 percent. Five coal samples of varying ash content were taken to compare the results of MM obtained by existing correlations and experimental MM. The ash of these samples ranges from 30.7 to 45.3 percent. Their MM were determined by all existing correlations viz. KMC formula, modified KMC formula and modified Parr formula. Their MM was also determined by Plasma asher. All results were plotted as a function of ash content (Figure 1). Significant deviations have been observed in all the results from experimental MM at high ash level. The Gondwana coals, from which the thermal coals are drawn, are generally found to be intimately mixed with fairy large proportion of mineral matter resulting in ash yields of 30 to 60 percent on air dried basis [11].

\section{Existing Correlations}

A number of different correlations have been reported that purport to allow the calculation of mineral matter content of coals from the high temperature ash yield. These correlations are based on chemical analysis of the ash in coal as well as on some assumptions.

Parr in 1928 proposed a correlation based on the ash yield of coal and total sulphur content, assuming that all the sulphur present in coal is pyritic, and represented as

$$
\mathrm{MM}=1.08 \mathrm{~A}+0.55 \mathrm{~S}
$$

Given and Yarzeb in 1978 [12] modified the correlation as

$$
\mathrm{MM}=1.13 \mathrm{~A}+0.47 \mathrm{~S}_{\text {pyr. }}+0.5 \mathrm{Cl}
$$

They incorporate pyritic sulphur and chlorine in the correlation instead of total sulphur. Later this is further modified for high ash indian coal as

$$
\mathrm{MM}=1.1 \mathrm{~A}
$$

This is called modified Parr formula and generally used for the calculation of mineral matter in Indian coals.

King-Maries-Crossley (KMC) in 1936 reported a correlation based on carbonate carbon, pyritic and sulphatesulphur, chlorine, ash yield and the proportion of the sulphur retained in the coal ash assuming the water of hydration of clay is $8 \%$, three parts of $\mathrm{FeS}_{2}$ forms two parts of $\mathrm{Fe}_{2} \mathrm{O}_{3}$ and that half the chlorine is inorganically combined and represented as

$$
\mathrm{MM}=1.13 \mathrm{~A}+0.5 \mathrm{~S}_{\mathrm{pyr}}+0.8 \mathrm{CO}_{2}+2.85 \mathrm{~S}_{\mathrm{SO}_{4}}-2.85 \mathrm{~S}_{\mathrm{ash}}+0.5 \mathrm{Cl}
$$

Fereday and Flint [13] have modified this as

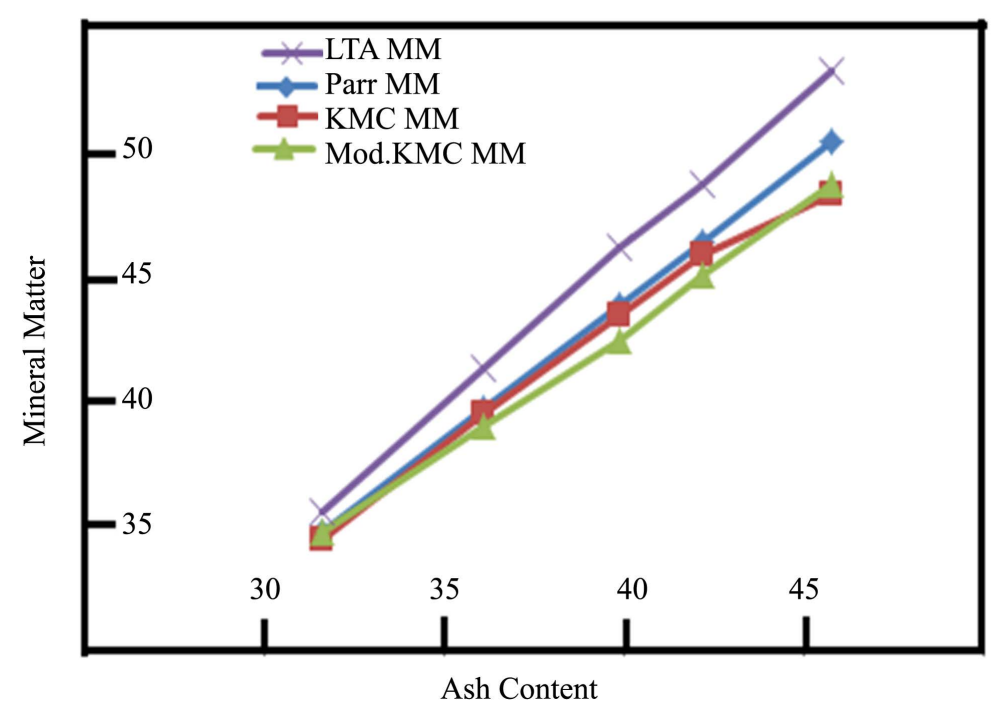

Figure 1. Comparison of MM obtained by different correlations. 


$$
\mathrm{MM}=1.06 \text { Ash }+0.53 \mathrm{~S}+0.74 \mathrm{CO}_{2}-0.33
$$

The common objections to these correlations are that they have to assume that the clay minerals in coals have constant average water of decomposition, and that they ignore the possible presence of quartz, which yields no water of decomposition on heating [14]. The KMC formula has been most commonly used in Britain, where all commercially significant coals are of carboniferous age and of a restricted range of rank. On the other hand Indian coal varies widely as it formed in number of geological eras and covering a wider range of rank.

Another method reported by Radmacher and Mohrhauer in 1955 [15], which involve the acid treatment of coal and resulting the removal of mineral matter content. The method involves the digestion of the mineral components in hydrochloric and hydrofluoric acid. The loss due to digestion was reported as mineral matter in coal. A number of different modern instrumental techniques [16]-[26] have been used for the quantification of mineral matter in coal which involve separate determination of non-mineral inorganics, megascopic and microscopic methods, scanning electron microscopy, electron microprobe analysis, thermal analysis techniques, X-ray diffraction analysis and normative methods etc. All these techniques involve higher cost of instruments besides the need of highly skilled operator.

Keeping the above in view, it is necessary to develop a reliable correlation which can predict mineral matter in high ash Indian coals. To minimize the efforts and time involved in calculating the mineral matter by existing correlation, it is also desirable to develop a correlation based on simple parameters.

\section{Experimental}

Coal samples were collected from different coalfields viz. North Karanpura, South Karanpura, Ramgarh, East Bokaro, West Bokaro, Talcher and from CCL command area in Jharkhand and Orissa. All samples were crushed to pass 212 micron sieve. The size of the samples was reduced by coning and quartering method and representative sample were taken for each coal. The proximate analyses of air dried samples were determined by thermogravimetric analyzer (LECO, TGA-701) following ASTM-D 5142. The mineral matter of dried coal samples were determined by single chamber oxygen plasma asher (Emitech K1050X with external No. 3 rotary Fomblin pump). The operating power was fixed on $50 \mathrm{~W}$, while the ashing time and frequency of stirring were taken as variables. All results were corrected for residual carbon by treating low temperature ash with dilute hydrochloric acid and subsequent determination of Carbon by CHNS analyzer (ELEMENTAR, Model-Vario Macro Cube) following ASTM D5373. The effect of sulphate-sulphur fixation does not taken into account as all sample have low sulphur $(<0.5 \%)$ content.

\section{Development of Correlation}

The results of the all 75 coal samples comprises proximate and mineral matter are divided in to two parts. Out of 75 data, 50 data were used to develop the correlation and shown in Table 1, and 25 data were kept for validation purpose (Table 2). MM were plotted against the added values of moisture content and ash content and seen in Figure 2. From the plot it is clear that both the parameter have positive impact on mineral matter. The impact of VM and FC were also studied Figure 3 and Figure 4. It was observed that both the parameter have poor correlation as compared to moisture and ash and have negative impact on mineral matter. Hence it has been decided that both the variables will be used to develop the correlation.

Multiple regression analysis has been used to find the linear correlation between the independent variables i.e. moisture and ash yield and dependent variable i.e. mineral matter by fitting a linear equation to the observed data. Each value of independent variable $(X)$ is associated with a value of the dependable variable $(Y)$. The regression equation for $\mathrm{n}$ independent variables is defined to be as

$$
\mathrm{Yi}=a+b_{1} \mathrm{X}_{1}+b_{2} \mathrm{X}_{2}+\cdots+b_{n} \mathrm{X}_{\mathrm{n}}
$$

where $b$ are the regression coefficient and $a$ is the intercept. Relationship between the variables is then plotted to identify the trend that has the best fit. The best fitted trend is selected based on the minimum value of the sum of squares of deviation of the various data points from the line obtained. The best possible values of the regression coefficient in the equation are determined by the method of least square. Regression equations obtained in this analysis were compared on the basis of coefficient of multiple determinations. The coefficient of determination $\left(R^{2}\right)$ of a multiple linear regression model is the quotient of the variances of the fitted values and observed values of the dependent variable. If we denote $y_{i}$ as the observed values of the dependent variable, $\bar{y}$ as its mean, 
Table 1. Statement of the results of 50 coal samples.

\begin{tabular}{|c|c|c|c|c|c|}
\hline \multirow{2}{*}{ Sample Sr. No. } & \multicolumn{5}{|c|}{ (Air Dried) } \\
\hline & M\% & $\mathbf{A} \%$ & VM\% & FC\% & МM\% \\
\hline 1. & 5.1 & 27.3 & 24.6 & 43.0 & 35.32 \\
\hline 2. & 6.0 & 36.6 & 23.8 & 33.6 & 46.44 \\
\hline 3. & 5.2 & 36.3 & 25.4 & 33.1 & 46.72 \\
\hline 4. & 5.9 & 36.5 & 23.7 & 33.9 & 45.88 \\
\hline 5. & 5.4 & 36.2 & 25.2 & 33.2 & 45.35 \\
\hline 6. & 7.3 & 36.8 & 26.5 & 29.4 & 46.35 \\
\hline 7. & 8.1 & 34.4 & 26.4 & 31.1 & 43.5 \\
\hline 8. & 3.3 & 55.3 & 17.5 & 23.9 & 69.08 \\
\hline 9. & 6.9 & 44.7 & 22.9 & 25.5 & 57.45 \\
\hline 10. & 6.8 & 40.3 & 25.1 & 27.8 & 50.93 \\
\hline 11. & 7.2 & 33.7 & 27.0 & 32.1 & 42.47 \\
\hline 12. & 8.1 & 29.9 & 25.4 & 36.6 & 47.73 \\
\hline 13. & 6.4 & 35.0 & 32.6 & 26.0 & 45.28 \\
\hline 14. & 6.9 & 27.5 & 31.9 & 33.7 & 39.65 \\
\hline 15. & 6.8 & 20.3 & 25.4 & 47.5 & 27.34 \\
\hline 16. & 6.8 & 16.6 & 28.2 & 48.4 & 23.61 \\
\hline 17. & 8.7 & 14.6 & 30.4 & 46.3 & 23.33 \\
\hline 18. & 5.2 & 13.5 & 29.8 & 51.5 & 20.75 \\
\hline 19. & 5.6 & 52.5 & 18.3 & 23.6 & 67.7 \\
\hline 20. & 4.4 & 38.2 & 27.2 & 30.2 & 45.64 \\
\hline 21. & 4.7 & 32.1 & 25.6 & 37.6 & 41.91 \\
\hline 22. & 5.2 & 28.1 & 26.4 & 40.3 & 37.0 \\
\hline 23. & 6.3 & 26.3 & 27.3 & 40.1 & 35.2 \\
\hline 24. & 3.7 & 25.3 & 29.8 & 41.2 & 35.24 \\
\hline 25. & 4.2 & 19.7 & 32.6 & 43.5 & 29.47 \\
\hline 26. & 4.9 & 17.3 & 35.3 & 42.5 & 27.11 \\
\hline 27. & 4.0 & 36.8 & 22.3 & 36.9 & 50.18 \\
\hline 28. & 3.9 & 41.7 & 17.4 & 37.0 & 53.81 \\
\hline 29. & 3.3 & 48.1 & 21.0 & 27.6 & 63.77 \\
\hline 30. & 2.0 & 46.0 & 20.0 & 32.0 & 55.65 \\
\hline 31. & 1.2 & 45.3 & 20.4 & 33.1 & 53.25 \\
\hline 32. & 0.8 & 60.6 & 15.5 & 23.1 & 72.68 \\
\hline 33. & 1.1 & 49.2 & 18.3 & 31.4 & 59.45 \\
\hline 34. & 1.0 & 41.4 & 18.5 & 39.1 & 48.85 \\
\hline 35. & 5.2 & 17.4 & 27.4 & 50.0 & 23.89 \\
\hline 36. & 6.2 & 51.1 & 25.2 & 17.5 & 63.87 \\
\hline
\end{tabular}




\section{Continued}

\begin{tabular}{llllll}
\hline 37. & 1.9 & 39.9 & 15.2 & 43.0 & 48.69 \\
38. & 1.4 & 36.7 & 19.3 & 42.6 & 42.61 \\
39. & 1.1 & 23.2 & 19.8 & 55.9 & 25.94 \\
40. & 1.5 & 65.2 & 6.9 & 26.4 & 75.24 \\
41. & 6.8 & 36.3 & 25.1 & 31.8 & 45.11 \\
42. & 3.2 & 31.6 & 4.4 & 60.8 & 38.65 \\
43. & 5.1 & 18.4 & 24.8 & 51.7 & 22.69 \\
44. & 3.2 & 29.4 & 10.3 & 37.1 & 35.64 \\
45. & 4.1 & 32.4 & 24.4 & 34.1 & 39.87 \\
46. & 6.4 & 34.0 & 25.6 & 46.6 & 42.17 \\
47. & 1.9 & 36.7 & 14.8 & 37.9 & 43.65 \\
48. & 1.2 & 48.8 & 12.1 & 46.2 & 57.96 \\
49. & 1.0 & 27.7 & 25.1 & 48.7 & 31.42 \\
50. & 1.2 & 36.6 & 13.5 & 39.14 \\
\hline
\end{tabular}

Table 2. Comparison of experimental MM and predicted MM by proposed correlation.

\begin{tabular}{|c|c|c|c|c|c|c|c|}
\hline Sample Sr. No. & M\% & A\% & VM\% & FC\% & $\begin{array}{c}\text { MM } \\
\text { Experimental }\end{array}$ & $\begin{array}{l}\text { MM Predicted } \\
\text { by Equation (9) }\end{array}$ & Absolute Error \\
\hline 51. & 6.2 & 51.1 & 25.2 & 17.5 & 63.81 & 64.38 & 0.57 \\
\hline 52. & 8.4 & 19.2 & 28.2 & 44.2 & 26.23 & 28.68 & 2.45 \\
\hline 53. & 5.2 & 41.6 & 21.0 & 32.2 & 50.74 & 52.52 & 1.78 \\
\hline 54. & 7.6 & 23.3 & 30.7 & 38.4 & 30.65 & 32.89 & 2.24 \\
\hline 55. & 2.0 & 24.4 & 28.7 & 44.9 & 28.91 & 30.03 & 1.12 \\
\hline 56. & 2.1 & 33.2 & 19.8 & 44.9 & 39.16 & 40.40 & 1.24 \\
\hline 57. & 2.4 & 25.7 & 21.1 & 50.8 & 30.54 & 31.85 & 1.31 \\
\hline 58. & 3.1 & 45.7 & 20.7 & 30.5 & 53.89 & 55.76 & 1.87 \\
\hline 59. & 3.1 & 54.6 & 17.8 & 24.5 & 62.92 & 66.18 & 3.26 \\
\hline 60. & 1.0 & 27.3 & 18.7 & 53.0 & 30.87 & 32.68 & 1.81 \\
\hline 61. & 3.4 & 19.8 & 34.1 & 42.7 & 24.87 & 25.68 & 0.81 \\
\hline 62. & 7.4 & 11.5 & 31.4 & 49.7 & 18.94 & 18.93 & 0.01 \\
\hline 63. & 9.1 & 27.5 & 26.7 & 36.7 & 38.27 & 38.91 & 0.64 \\
\hline 64. & 8.3 & 52.7 & 4.1 & 34.9 & 64.53 & 67.80 & 3.27 \\
\hline 65. & 2.4 & 21.9 & 7.0 & 68.7 & 25.46 & 27.40 & 1.94 \\
\hline 66. & 2.6 & 21.6 & 8.3 & 67.5 & 26.18 & 27.20 & 1.02 \\
\hline 67. & 1.6 & 42.0 & 12.0 & 44.4 & 48.80 & 50.32 & 1.52 \\
\hline 68. & 2.1 & 35.6 & 24.4 & 37.9 & 43.12 & 43.21 & 0.09 \\
\hline 69. & 2.3 & 24.6 & 25.8 & 47.3 & 30.10 & 30.48 & 0.38 \\
\hline 70. & 2.2 & 12.1 & 29.6 & 56.1 & 14.18 & 15.79 & 1.61 \\
\hline 71. & 0.7 & 58.5 & 15.7 & 25.1 & 67.23 & 68.96 & 1.73 \\
\hline 72. & 5.5 & 27.6 & 29.1 & 37.8 & 35.87 & 36.36 & 0.49 \\
\hline 73. & 1.2 & 33.8 & 10.9 & 54.1 & 41.07 & 40.43 & 0.64 \\
\hline 74. & 5.1 & 50.9 & 18.3 & 25.7 & 65.24 & 63.33 & 1.91 \\
\hline 75. & 1.9 & 46.9 & 20.7 & 30.5 & 56.21 & 56.28 & 0.07 \\
\hline
\end{tabular}




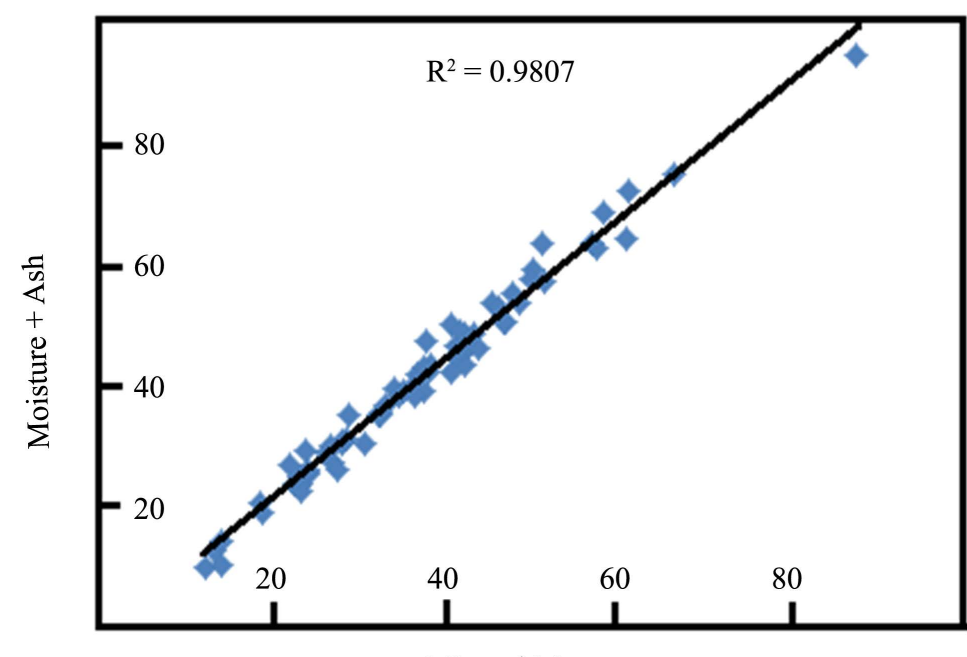

Mineral Matter

Figure 2. Variation of MM with added values of moisture and ash content.

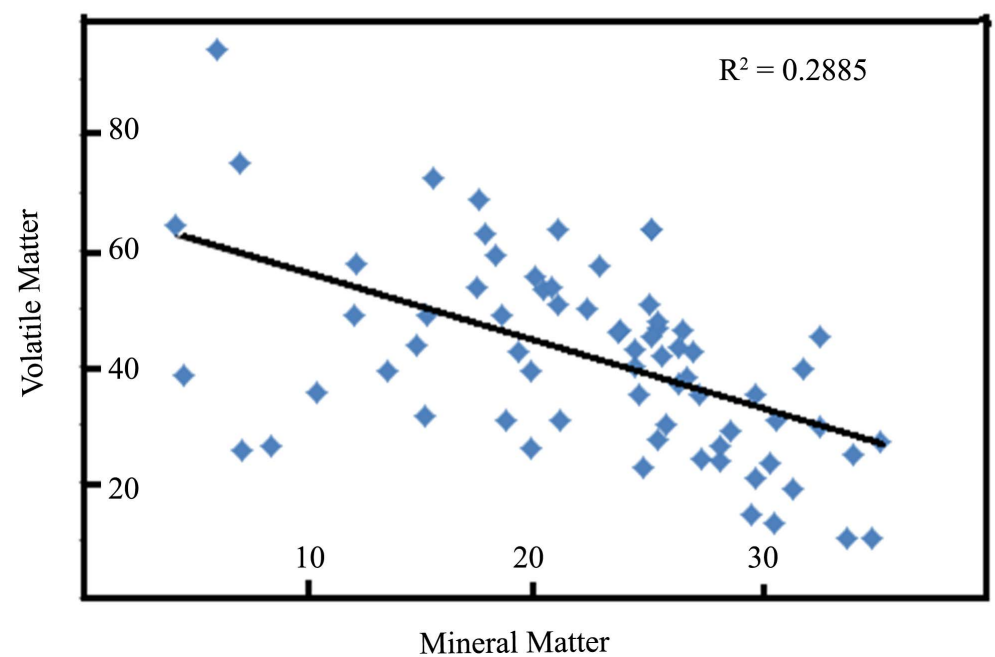

Figure 3. Variation of MM with volatile matter.

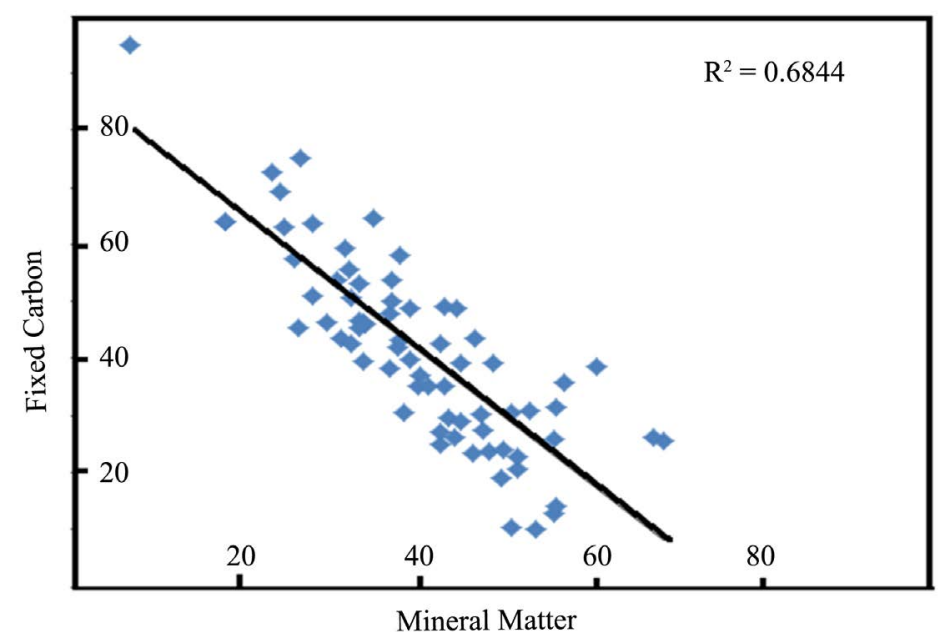

Figure 4. Variation of MM with fixed carbon. 
and $\hat{y}_{i}$ as the fitted value, then the coefficient of determination is

$$
R^{2}=\frac{\sum\left(\hat{y}_{i}-\bar{y}\right)^{2}}{\sum\left(y_{i}-\bar{y}\right)^{2}}
$$

The equation with $R^{2}$ value close to one is selected to be the best. A generalized correlation (Equation (8)) in the given form having $R^{2}$ value 0.99 was thus produced after checking the suitability of the equation for all the parameters.

$$
Y=b X_{1}+c X_{2}
$$

where $X_{1}$ and $X_{2}$ are moisture and ash yield and $Y$ is the mineral matter content of coal. After incorporating the respective values of the coefficient in the equation the final correlation appears to be as

$$
\mathrm{MM}=0.74(\mathrm{M})+1.17(\mathrm{~A})
$$

where MM is mineral matter while $\mathrm{M}$ and $\mathrm{A}$ are the moisture and ash yield respectively on air dried basis. The independent variables are in weight percentage on air-dried basis. The results obtained by the developed correlation are in fairly good agreement with those determined experimentally. Both the results were platted and discussed later.

\section{Results and Discussion}

The proposed correlation has developed considering wide range of coal samples from the different regions of India. The moisture of the coals range from 1.0 to 8.7 percent and ash vary from 13.5 to 65.2 percent on air dried basis. The value for volatile matter ranges from 4.4 to 35.3 percent and the values of fixed carbon ranges from 17.5 to 60.8 percent. The coal samples ranged from low to high ash yield. The validity of the proposed correlation was also established with the 25 coal sample data kept separately. The results obtained with the help of proposed correlation were compared with those determined experimentally (Figure 5). The plot shows that there is a good agreement in two data with $\mathrm{R}^{2}$ value more than 0.99 . The average absolute error between the experimental and predicted data is found to be very low and calculated to be $1.35 \%$. The low error establishes the validity of the proposed equation.

\section{Conclusion}

A correlation has been developed based on air dried moisture and ash yield which gives a better estimation of the mineral matter compared to the existing relations. Selection of a wide range of moisture and ash percent makes this correlation versatile. The validity of the correlation has been established with the experimentally determined data. Hence, the proposed correlation may be used for the calculation of mineral matter in high ash Indian coal.

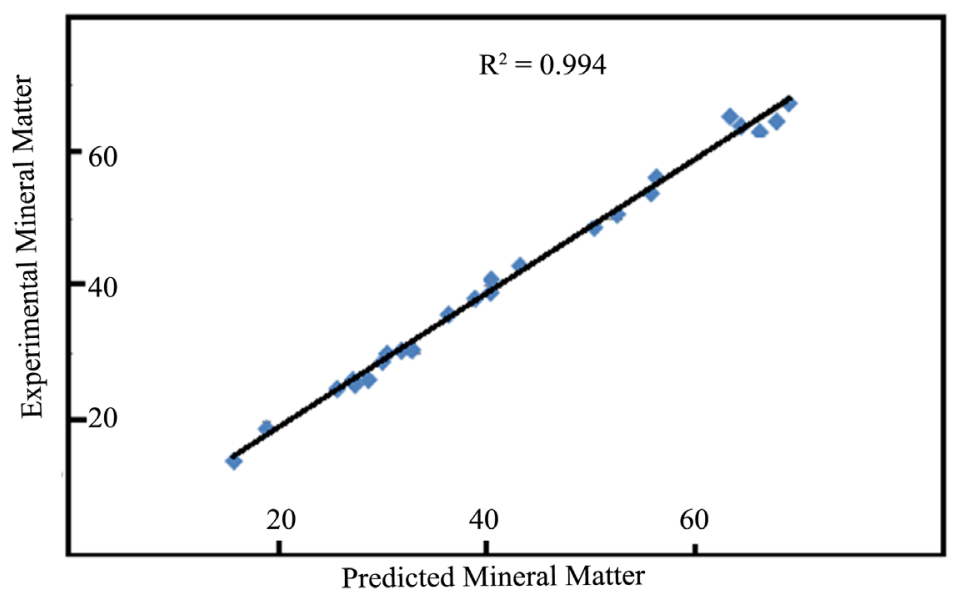

Figure 5. Comparison of measured MM with predicted MM. 


\section{Acknowledgements}

The authors are thankful to the Director, CSIR_Central Institute of Mining \& Fuel Research, Dhanbad for his kind permission to publish this paper. The authors are also thankful to Mr. Asim Choudhury of CIMFR Digwadih Campus for his valuable suggestion and support in improving the paper. The authors extend their thanks to Dr. M. L. Banra, Dr. S. K. Laha, Dr. M. Kumar, A. Chakravorty and Dr. M. Jha, of CIMFR unit Ranchi for their cooperation in sample preparation and chemical analysis.

\section{References}

[1] Ward, C.R. (2002) Analysis and Significance of Mineral Matter in Coal Seams. International Journal of Coal Geology, 50, 135-168. http://dx.doi.org/10.1016/S0166-5162(02)00117-9

[2] Dwari, R.K. and Rao, K.H. (2006) Tribo-Electrostatic Behavior of High Ash Non-Coking Indian Thermal Coal. International Journal of Mineral Processing, 81, 93-104. http://dx.doi.org/10.1016/j.minpro.2006.07.006

[3] Choudhury, N., Boral, P., Mitra, T., Adak, A.K., Choudhury, A. and Sarkar, P. (2007) Assessment of Nature and Distribution of Inertinite in Indian Coals for Burning Characteristics. International Journal of Coal Geology, 72, 141-152. http://dx.doi.org/10.1016/j.coal.2006.12.011

[4] Van Krevelen, D.W. (2005) Coal: Typology-Physics-Chemistry-Constitution. Elsevier, Amsterdam.

[5] Gupta, R., Wall, T.F. and Baxter, L.A. (1999) The Impact of Mineral Impurities in Solid Fuel Combustion. Plenum, New York.

[6] Huggins, F.E. (2002) Overview of Analytical Methods for Inorganic Constituents in Coal. International Journal of Coal Geology, 50, 169-214. http://dx.doi.org/10.1016/S0166-5162(02)00118-0

[7] Brown, H.R., Durie, R.A. and Schafer, H.N.S. (1959) The Inorganic Constituents of Australian Coals: The Direct Determination of the Total Mineral Matter Content. Fuel, 38, 295-308.

[8] Gluskoter, H.J. (1965) Electronic Low Temperature Ashing of Bituminous Coal. Fuel, 44, 285-291.

[9] Frazer, F.W. and Belcher, C.B. (1973) Quantitative Determination of the Mineral Matter Content of Coal by Radio Frequency Oxidation Technique. Fuel, 52, 41-46. http://dx.doi.org/10.1016/0016-2361(73)90010-0

[10] Standards Australia, Higher Rank Coal-Mineral Matter and Water of Constitution. Australian Standard, 1083, Part 2, 22.

[11] Bandopadhyay, A.K. (2010) Determination of Quartz Content for Indian Coals Using an FTIR Technique. International Journal of Coal Geology, 81, 73-78. http://dx.doi.org/10.1016/j.coal.2009.10.018

[12] Given, P.H. and Yarzeb, R.F. (1978) Analysis of the Organic Substance in Coal; Problems Posed by the Presence of Mineral Matter. In: Karr, C., Ed., Analytical Methods for Coal and Coal Products, Vol. II, Academic Press, New York.

[13] Fereday, F. and Flint, D. (1953) Fuel. Butterworths Scientific Publications, London.

[14] Miller, R.N., Yarzab, R.F. and Given, P.H. (1979) Determination of the Mineral-Matter Contents of Coals by LowTemperature Ashing. Fuel, 58, 4-10. http://dx.doi.org/10.1016/0016-2361(79)90044-9

[15] Rammacher, W. and Mohrhauer, P. (1955) The Direct Determination of the Mineral Matter Content of Coal. Brennstoff-Chemie, 36, 236.

[16] Mitra, G.B. (1954) Identification of Inorganic Impurities in Coal by X-Ray Diffraction. Fuel, 33, 316-329.

[17] Gluskoter, H.J. (1967) Clay Minerals in Illinois Coals. Fuel, 44, 285-291.

[18] Rietveld, H.M. (1969) A Profile Refinement Method for Nuclear and Magnetic Structures. Journal of Applied Crystallography, 2, 65-71. http://dx.doi.org/10.1107/S0021889869006558

[19] Pollack, S.S. (1979) Estimating Mineral Matter in Coal from Its Major Chemical Components. Fuel, 58, 76-78. http://dx.doi.org/10.1016/0016-2361(79)90061-9

[20] Ward, C.R. (1991) Mineral Matter in Low-Rank Coals and Associated Strata of the Mae Moh Basin, Northern Thialand. International Journal of Coal Geology, 17, 69-93. http://dx.doi.org/10.1016/0166-5162(91)90005-4

[21] Ward, C.R. (1992) Mineral Matter in Triassic and Tertiary Low-Rank Coals from South Australia. International Journal of Coal Geology, 20, 185-208. http://dx.doi.org/10.1016/0166-5162(92)90013-M

[22] Ward, C.R. and Taylor, J.C. (1996) Quantitative Mineralogical Analysis of Coals from the Callide Basin, Queensland, Australia Using X-Ray Diffractometry and Normative Interpretation. International Journal of Coal Geology, 31, 211229. http://dx.doi.org/10.1016/0166-5162(95)00044-5

[23] Hower, J.C., Calder, J.H., Eble, C.F., Scott, A.C., Robertson, J.D. and Blanchard, L.J. (2002) Metalliferous Coals of the Westphalian A Joggins Formation, Cumberland Basin, Nova Acotia, Canada: Petrology, Geochemistry and Paly- 
nology. International Journal of Coal Geology, 42, 185-206. http://dx.doi.org/10.1016/S0166-5162(99)00039-7

[24] Van Geet, M., Swennen, R. and David, P. (2001) Quantitative Coal Characterization by Means of Microfocus X-Ray Computer Tomography, Colour Image Analysis and Black Scattered Scanning Electron Microscopy. International Journal of Coal Geology, 46, 11-25. http://dx.doi.org/10.1016/S0166-5162(01)00006-4

[25] Suphi, U. (2007) Quantification of Crystalline (Mineral) Matter in Some Turkish Coals Using Interactive RietveldBased X-Ray Diffractometry. International Journal of Coal Geology, 71, 176-184. http://dx.doi.org/10.1016/j.coal.2006.08.002

[26] Grigore, M., Sakurovs, R., French, D. and Sahajwalla, V. (2008) Mineral Matter in Coals and Their Reactions during Coking. International Journal of Coal Geology, 76, 301-308. http://dx.doi.org/10.1016/j.coal.2008.08.013 